\title{
Implementasi Algoritma k-Nearest Neighbor untuk Penjurusan Siswa SMA
}

\author{
Christiandita Rahayuningtyas $^{1}$, Dedy Satrio Winarso ${ }^{2}$ \\ ${ }^{1}$ Program Studi S1 Teknik Informatika, STT Cahaya Surya Kediri \\ ${ }^{2}$ Teknik Informatika, STT Cahaya Surya Kediri \\ E-mail: 1dietha.vcr93@gmail.com,_dedy@cahayasurya.ac.id
}

\begin{abstract}
Abstrak
SMA Negeri 5 Kediri merupakan sebuah lembaga pendidikan yang berada di Kediri. Pada SMA Negeri 5 Kediri terdapat 2 jurusan yaitu IPA dan IPS yang dilakukan pada saat kelas $\mathrm{X}$ dimana para siswa sering kali mengalami kesulitan dalam menetukan jurusan yang sesuai. Hal ini disebabkan oleh sistem dari penjurusan yang masih tidak sesuai dengan kemampuan siswa yang dimiliki. Penelitian ini dilakukan untuk menghasilkan model data untuk sistem pendukung keputusan penentuan jurusan dengan memadukan sebuah algoritma k-NN (k-Nearest Neighbor). k-NN merupakan algoritma yang melakukan klasifikasi terhadap suatu objek yang dijadikan training untuk diolah hingga menemukan tingkat kevalidannya berdasarkan data pembelajaran dimana data tersebut merupakan data terdekat untuk diolah kedalam data uji. Sistem pendukung keputusan ini merupakan salah satu sistem yang cukup efisien karena sistem tersebut sudah terkomputerisasi, tidak lagi secara manual sehingga dapat mengatasi masalah dalam menentukan jurusan.
\end{abstract}

Kata Kunci-Sistem Pendukung Keputusan, k-Nearest Neighbor, Penjurusan Siswa

\section{PENDAHULUAN}

Sistem Pendukung Keputusan adalah sebuah sistem yang mampu memberikan kemampuan pemecahan masalah maupun kemampuan pengkomunikasian untuk masalah dengan kondisi semi terstruktur dan tak terstruktur. Para ahli komputer mencoba membangun sistem komputer yang dapat membantu mengambil suatu keputusan. Melalui sistem pendukung keputusan akan mengurangi risiko kesalahan yang dapat terjadi karena keterbatasan manusia. Sistem pendukung keputusan ini dilengkapi dengan adanya data mining, data Mining adalah serangkaian proses untuk menggali nilai tambah berupa informasi yang selama ini tidak diketahui secara manual dari suatu basis data dengan melakukan penggalian pola-pola dari data dengan tujuan untuk memanipulasi suatu data menjadi suatu informasi yang lebih jelas dan berharga yang diperoleh dengan cara memecah dan mengenali pola yang penting atau menarik dari data yang terdapat dalam basis data.

Konsep dasar data mining banyak digunakan untuk sistem pendukung keputusan yang digunakan khususnya pada bidang penjurusan SMA. Sesuai kurikulum 2004 pada sekolah menengah tingkat atas memiliki penjurusan setiap peserta didik yang akan naik ke kelas XI. Pada SMA Negeri 5 Kediri penjurusan dibagi menjadi 2, yaitu IPA dan IPS. Penjurusan merupakan salah satu proses bagian penempatan dalam pemilihan program pengajaran oleh siswa sesuai dengan kompetensi yang di miliki oleh siswa di 
SMA. Tujuannya pelajaran yang akan diberikan kepada siswa menjadi lebih terarah karena telah sesuai dengan kemampuan pada bidang minatnya. Permasalahan yang ada ini tentunya akan mengganggu kelancaran belajar para siswa SMA. Oleh karena itu, perlu adanya aplikasi sistem pendukung keputusan bagi para siswa SMA guna membantu dalam menentukan jurusan sesuai dengan kemampuan akademiknya.

Klasifikasi data mining banyak digunakan sistem pendukung keputusan karena klasifikasi untuk mengetahui konsep training dan ujinya. Algoritma k-NN memiliki tingkat akurasi yang terus meningkat sehingga penggunaan algoritma k-NN ini sangat berpengaruh pada penentuan penjurusan SMA [1]. Selain itu menghitung nilai kemiripan atau jarak vektor data pada testing terhadap data yang akan digunakan sebagai data training. Selanjutnya akan diambil sejumlah k tetangga terdekat sesuai hasil penghitungan kemiripan atau jarak. Kemudian dilakukan penghitungan apakah cocok dengan data manual pada data testing [2]. Data testing diklasifikasi kedalam kelas kategori yang memiliki nilai kesamaan kelas untuk data testing yang paling tinggi.

Sekian banyaknya algoritma klasifikasi yang ada, k-Nearest Neighbor (K-NN) menjadi algoritma yang memiliki daya tarik tersendiri. k-NN merupakan teknik klasifikasi yang sederhana dengan prinsip memilih tetangga terdekat untuk menghitung jumlah datanya. Oleh karena itu model pengukuran jarak menjadi penting untuk dipertimbangkan. Karena dimana metode k-NN memiliki ketangguhan terhadap data sample yang memiliki banyak noise dan juga sangat efektif apabila data trainingnya besar [3]. Sehingga k-NN mampu menyelesaikan permasalahan tentang penjurusan di SMA Negeri 5 Kediri.

\section{METODE PENELITIAN}

Metode pengumpulan data yang penulis gunakan dalam penyusunan tugas akhir ini adalah pengumpulan data dengan melakukan pengamatan langsung di lapangan. Adapun teknik pengumpulan data yang digunakan antara lain :

\subsection{Pengumpulan Data (Data Collecting)}

Data Sampel diambil dari data siswa kelas XII, dengan nilai rata-rata $>85$ untuk IPA karena nilai 85 merupakan nilai minimal untuk dapat masuk jurusan IPA dan $>79$ untuk IPS karena nilai 79 merupakan nilai minimal untuk masuk dalam jurusan IPS. Total data yang didapatkan yaitu sekitar 334 sampel. Data sampel yang diambil dimulai dari pendataan siswa, data nilai raport (IPA, IPS), nilai kelas X.

Mengacu pada pendapat Arikunto yaitu apabila subjek kurang dari 100, maka lebih baik di ambil data seluruhnya, sehingga penelitiannya merupakan penelitian populasi. Selanjutnya jika jumlah subjeknya $>100$ dapat diambil antara $10 \%-15 \%$ atau $20 \%-25 \%$ itu untuk pengambilan sampel dengan populasi diatas 100 [4].

\subsection{Analisis dan Perancangan Sistem}

Pada tahap ini dilaksanakan perancangan sistem yang akan dibuat berdasarkan hasil studi literatur yang ada. Perancangan Perangkat Lunak ini meliputi desain database, desain struktur data, desain aliran informasi, desain antar muka, desain algoritma dan pemrograman.Desain-desain tersebut menggunakan aplikasi Power Designer dan Edraw Max agar perancangannya menjadi lebih efisien. Perancangan ini dengan membuat alur program, menentukan algoritma yang sesuai agar program dapat berjalan dengan baik dan efisien. 


\subsection{Implementasi}

Pembuatan program dibuat dengan program yang dirancang dengan bahasa pemrograman VB.Net dan implementasi dilakukan secara bertahap dengan acuan studi literatur dan perancangan sistem yang telah dibuat. Perancangan sistem yang telah dibuat akan diimplementasikan pada bahasa pemrograman yang telah disepakati.

\subsection{Pengujian dan Evaluasi}

Pada tahap ini dilakukan uji coba program untuk mencari masalah yang mungkin timbul, mengevaluasi jalannya program, dan mengadakan perbaikan jika ada kekurangan. Pengujian akurasi algoritma k-NN dengan menggunakan Confusion matrix. Algoritma k-Nearest Neighbor merupakan sebuah algoritma yang sering digunakan untuk klasifikasi teks dan data. Penggunaan k-Nearest Neighbor mempunyai sifat selflearning dimana jika semakin banyak dokumen, maka makin banyak pula sumber yang dapat digunakan untuk dibandingkan. K-Nearest Neighbor berarti mencari tetangga yang paling dekat dengan sets yang akan di klasifikasi [5].

k-NN dilakukan dengan mencari kelompok k objek dalam data training yang paling dekat (mirip) dengan objek pada data baru atau data testing. Algoritma K-Nearest Neighbor adalah sebuah metode untuk melakukan klasifikasi terhadap objek berdasarkan data pembelajaran yang jaraknya paling dekat dengan objek tersebut. Nearest Neighbor adalah pendekatan untuk mencari kasus dengan menghitung kedekatan antara kasus baru dan kasus lama yaitu berdasarkan pada pencocokan bobot dari sejumlah fitur yang ada. Langkah-langkah menghitung metode Algoritma k-Nearest Neighbor :

a. Tentukan parameter dari $K$

b. Hitung jarak antara data yang akan dievaluasi dengan semua pelatihan

c. Urutkan jarak yang terbentuk (urut naik)

d. Tentukan jarak terdekat sampai urutan $K$

e. Pasangkan kelas yang bersesuaian dan cocok

f. Cari jumlah kelas dari tetangga yang terdekat dan tetapkan kelas tersebut sebagai kelas data yang akan dievaluasi [2].

g. Dengan Penghitungan rumus KNN [3] sebagai berikut :

$$
d_{i}=\sqrt{\sum_{i=1}^{p}\left(x_{2 i}-x_{1 i}\right)^{2}}
$$

Keterangan:

$x_{1}=$ Sampel Data

$x_{2}=$ Data Uji / Testing

$i=$ Variabel Data

$d=$ Jarak

$p=$ Dimensi Data

Umumnya pengukuran kinerja klasifikasi dapat dilakukan dengan menggunakan matriks konfusi (confusion matrix). Untuk menghitung akurasi dapat menggunakan rumus di bawah ini:

$$
\text { Akurasi }=\frac{\text { Jumlah data yang terprediksi benar }}{\text { Jumlah prediksi yang dilakukan }}
$$


Sedangkan untuk mengukur laju error digunakan formula :

$$
\text { Laju error }=\frac{\text { Jumlah data yang terprediksi salah }}{\text { Jumlah prediksi yang dilakukan }}
$$

Semua algoritma klasifikasi berusaha membuat model dengan tingkat akurasi tinggi. Umumnya, model yang dibangun dapat memprediksi data latih (data training) dengan benar, tetapi ketika model berhadapan dengan data uji (data test), barulah kinerja model dari sebuah algoritma klasifikasi ditentukan [6].

\section{HASIL DAN PEMBAHASAN}

\subsection{Analisis Kebutuhan Sistem}

Sistem pendukung keputusan penentuan penjurusan siswa menggunakan algoritma $k$ Nearest Neighbor (K-NN) di SMA Negeri 5 Kediri ini, peneliti tidak hanya menganalisis data nilai mata pelajaran pendukung penjurusan yaitu data nilai IPA (Kimia, Fisika, Biologi), nilai IPS (Sosiologi, Geografi, Ekonomi), namun juga menganalisis dengan cara memperhitungkan konsep dimana alternatif terbaik yang hasilnya sesuai (valid) terhadap algoritma k-NN yang digunakan. Analisis tersebut yaitu analisa kebutuhan perangkat lunak. Pada tabel 1 adalah analisis kebutuhan perangkat lunak yang digunakan untuk perancangan sistem pendukungan keputusan penentuan penjurusan siswa di SMA Negeri 5 Kediri.

Tabel 1. Analisis Kebutuhan Perangkat Lunak

\begin{tabular}{|l|l|}
\hline Perangkat Lunak & \multicolumn{1}{|c|}{ Keterangan } \\
\hline Windows 7 Ultimate & Sistem operasi. \\
\hline $\begin{array}{l}\text { Microsoft Visual } \\
\text { Basic 2012 Ultimate }\end{array}$ & $\begin{array}{l}\text { Visual Basic Net adalah salah satu program } \\
\text { berorientasi objek. Menurut Ario Kusumo Suryo } \\
\text { (2000) program Visual Basic Net adalah } \\
\text { produksi Microsoft Corp. Program ini biasanya } \\
\text { dipaket bersama-sama dengan Visual C\# dan } \\
\text { Visual C++ dalam paket Visual Studio net. (Ario, } \\
\text { 2000) }\end{array}$ \\
\hline SQL Server 2008 & $\begin{array}{l}\text { SQL Server merupakan salah satu perangkat } \\
\text { lunak yang dapat dipakai untuk membuat suatu } \\
\text { database beserta file-file tabel yang berkaitan } \\
\text { dalam satu database. }\end{array}$ \\
\hline
\end{tabular}

\subsection{Data}

Pembuatan sistem pendukung keputusan penentuan penjurusan siswa dimulai dari pendataan data siswa kelas XII dan kelas X, data nilai rapot kelas XII (IPA dan IPS), data nilai kelas XII (nilai kelas X saat akan penjurusan), data nilai kelas X yang akan penjurusan yang ada di SMA Negeri 5 Kediri sebelum menentukan keputusan penentuan penjurusan. Setelah data terkumpul dapat dilihat dari ketentuan dan hasil setiap kriteria data nilai sehingga dapat diolah dengan menggunakan algoritma k-NN (kNearest Neighbor). 
Melalui hasil pengumpulan data sampel yang ada pada kelas XII, terdapat 334 sampel. Sampel yang diambil yaitu $25 \%$, karena populasi diatas 100 . Selain itu Data materi juga diperoleh dengan cara pencarian artikel lewat internet dan pembelajaran buku referensi. Setelah didapat sampel maka dilakukan pengumpulan nilai raport kelas $X$. Dikarenakan penjurusan kelas $X$ atribut yang digunakan yaitu mata pelajaran yang termasuk dalam IPA dan IPS, yaitu matematika, biologi, kimia, fisika, ekonomi, sejarah, geografi, sosiologi. Karena dalam mengacu klasifikasi dengan algoritma k-NN dibutuhkan atribut yang dimiliki sampel yang terpilih. Studi literatur dilaksanakan dengan cara mengumpulkan dan mempelajari segala macam informasi yang berhubungan dengan Penjurusan Siswa SMA, Sistem Pendukung Keputusan, Metode KNN (k-Nearest Neighbor) dan segala hal yang berhubungan dengan model pemrogramannya.

\subsection{Rancangan Alur Sistem}

Menggambarkan sebuah algoritma yang terstruktur dan mudah dipahami, maka dibutuhkan alat bantu yang berbentuk alur dari sebuah program. Pada gambar 1 merupakan flowchart alur program.

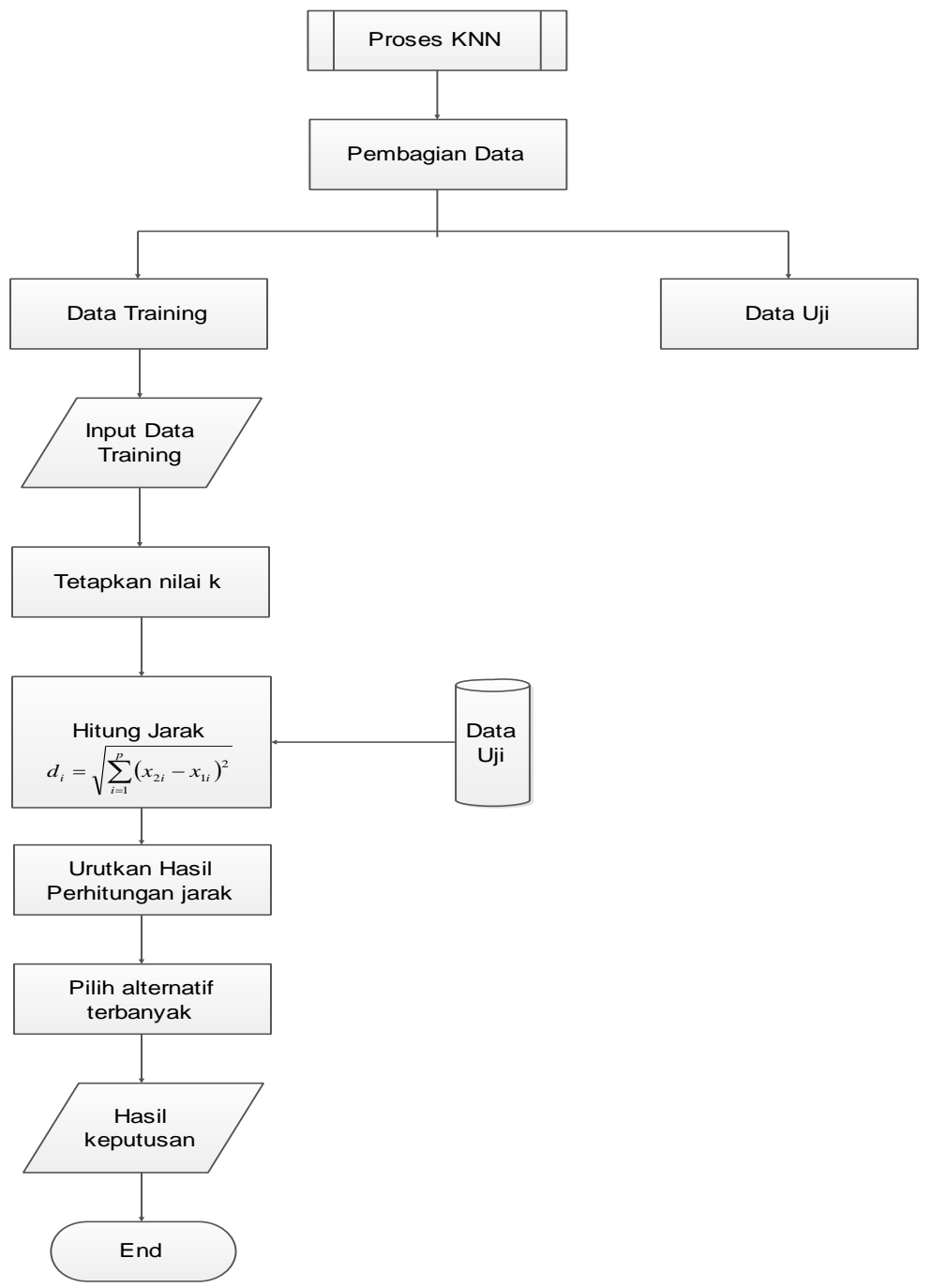

Gambar 1. Flowchart Alur Program 
Sedangkan pada gambar 2 merupakan flowchart alur implementasi algoritma k-NN. Pada proses implementasi algoritma

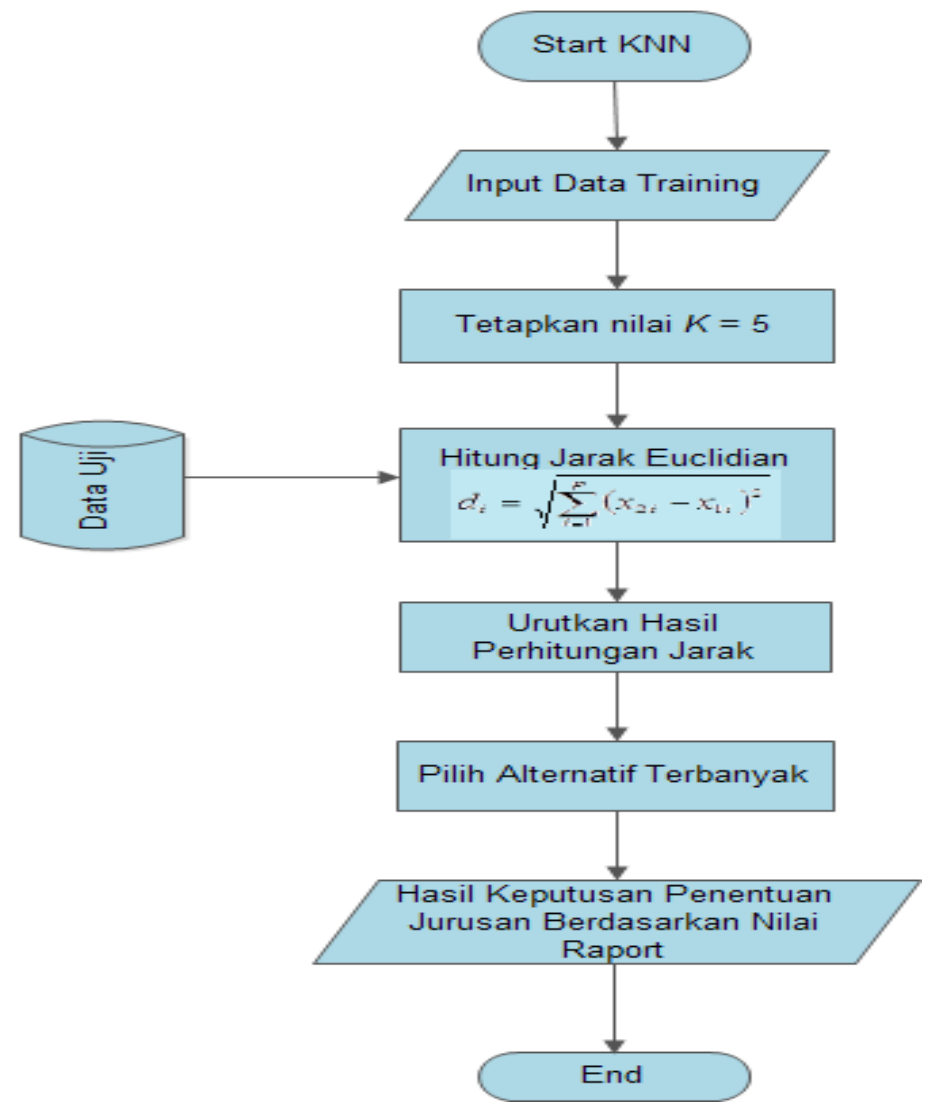

Gambar 2. Flowchart Algoritma k-NN

\subsection{User Interface}

Pada gambar 3 merupakan menu untuk input data nilai siswa yang digunakan sebagai data sampel.

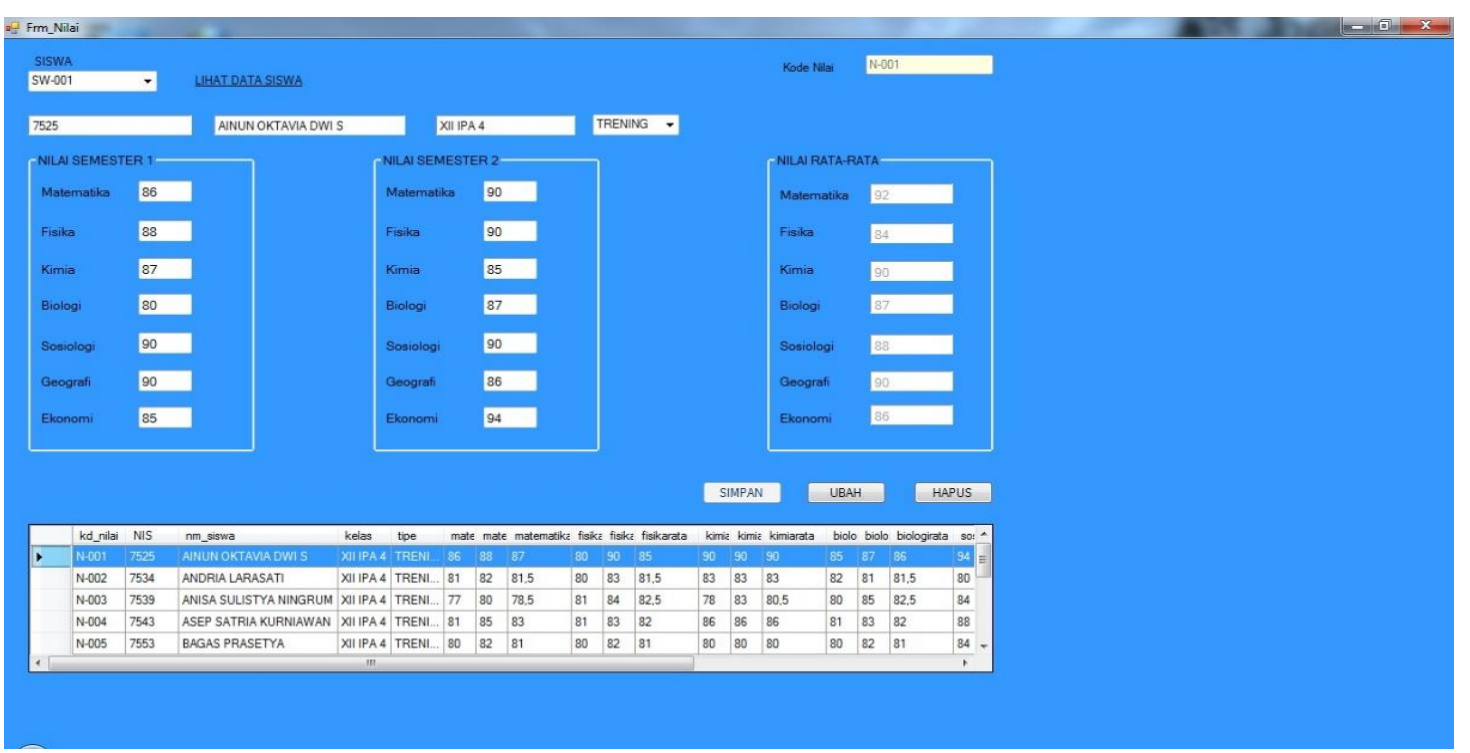

Gambar 3. Interface Menu Nilai Siswa 
Sedangkan pada gambar 4 merupakan interface untuk menu prediksi menggunakan algoritma k-NN.

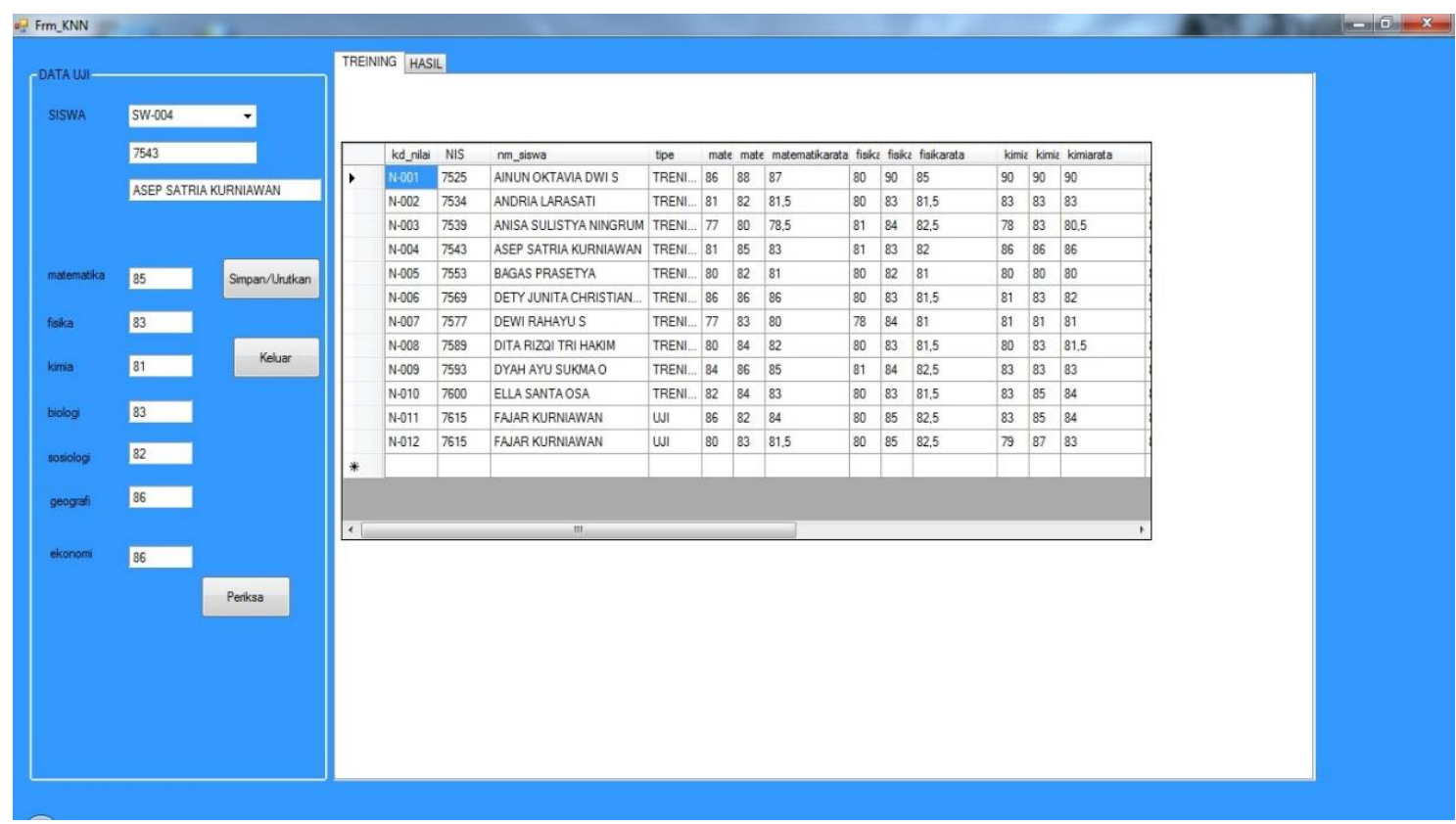

Gambar 4. Interface Menu k-Nearest Neighbor

\section{KESIMPULAN}

Melalui hasil implementasi dan evaluasi perancangan sistem pendukung keputusan penjurusan siswa menggunakan algoritma k-NN Pada SMA Negeri 5 Kediri sudah dapat memproses semua data yang ada baik mengenai informasi data siswa, data nilai, dan data penjurusan siswa. Sistem pendukung keputusan penjurusan siswa menggunakan algoritma k-NN telah dapat digunakan untuk data baru . Penambahan data siswa dan data nilai dapat dilakukan dan tersimpan dalam database. Diharapkan mengadakan pelatihan kepada admin khususnya guru Kesiswaan yang nantinya menjadi admin sistem yang telah dirancang. Sebaiknya program yang telah dirancang dan dibuat dapat dikembangkan lagi untuk mendapatkan hasil yang lebih baik lagi dan yang sesuai dengan kemajuan dan kebutuhan teknologi. Selain itu adanya perkembangan dari sistem yang sudah dibuat sehingga perkembangan sistem selanjutnya menjadi lebih memberikan kemudahan.

\section{DAFTAR PUSTAKA}

[1] Syaliman, L., B., Khairul., Ause, 2015, Analisa Lamda Model Jarak Minkowsky Untuk Penentuan Jurusan SMA(Studi Kasus di SMA Negeri 2 Tualang). JuTisI, No.2, Vol. 1, 163-171.

[2] Ndaumanu, R., I., Kusrini. Rudyanto, M., 2014, Analisis Pengunduran Diri Mahasiswa dengan Metode K-Nearest Neighbor. Jatisi, 1 No 1, 1-15.

[3] Kustiyaningsih, Y., Sistem Pendukung Keputusan Untuk Menentukan Jurusan Pada Siswa SMA Menggunakan Metode KNN dan Smart.

[4] Arikunto, S., 2006, Metodelogi Penelitian. Yogyakarta: Bina Aksara.

[5] Samuel, Y. D., 2014, Implementasi Metode k-Nearest Neighbor dengan Decision Rule untuk Klasifikasi Subtopik Berita. Jurnal Informatika, No.1,Vo.10, 1-15. 
[6] Sumarlin, 2015, Implementasi Algoritma K-Nearest Neighbor sebagai Pendukung Keputusan Klasifikasi Penerima Beasiswa PPA dan BBM, Jurnal Sistem Informasi Bisnis, 01, 52-62.

[4] Han, J., Kamber, M., Pei, J., 2012, Data Mining Concepts and Techniques, Ed. 3, Morgan Kaufmann, USA. 